\title{
Effect of adhesive type and glue-line thickness on the fatigue strength of mortise and tenon furniture joints
}

\begin{abstract}
The fatigue strength of rectangular mortise and tenon rubberwood furniture joints made from polyvinyl-acetate (PVAc) and urea-formaldehyde (UF) adhesives were compared. The results showed that the allowable design stress for PVAc adhesive joints could be set at $30 \%$ of its ultimate bending moment as compared to $25 \%$ for the UF adhesive joint. Further, PVAc adhesive joints have large working tolerances for glue-line thicknesses which make it suitable for mass production furniture manufacturing.
\end{abstract}

Keyword: Design stress; Fatigue strength; Furniture manufacturing; Mass production; Rubberwood; Urea formaldehyde 